\title{
El silencio de Guamán Poma de Ayala ante Supay: de duende, espíritu y fantasma a diablo
}

\author{
Rocío QuisPe-Agnoli \\ Michigan State University \\ quispeag@msu.edu \\ $\&$
}

\begin{abstract}
Resumen
En este artículo abordo muestras textuales del silencio u omisión que Guamán Poma de Ayala adopta frente a términos quechuas que designan lo sobrenatural y/o sagrado andino y se transforman, en los diccionarios coloniales y la historiografía españolas, en otredades malignas. Con este fin, analizo la retórica escrita e icónico-visual guamanpomiana alrededor de supay y diablo/demonio que llaman la atención por la ambivalencia discursiva que el autor crea y mantiene a lo largo de su obra. El tratamiento de supay, en comparación con el diablo del cristianismo, ofrece una respuesta alternativa a la lógica de la colonialidad planteada por Mignolo (2007). Esto, a su vez, permite leer la obra de Guamán Poma como un ejemplo de desprendimiento de la retórica de la modernidad que domina el género historiográfico acerca de América indígena.
\end{abstract}

Palabras clave: Supay, zorro, diablo, hechicero, silencio, resemantización.

\begin{abstract}
In this essay I examine textual examples of silence or omission used by Guamán Poma de Ayala before Quechua terms that refer to the Andean supernatural and/or sacred and its eventual change, in colonial dictionaries and Spanish historiography, in evil otherness. With this objective, I analyze Guamán Poma's written and iconic-visual rhetoric of supay and the devil/demon that reveal the discursive ambivalence created and maintained by the author throughout his work. When compared with the devil in Christianity, the treatment of supay offers an alternate answer to the logic of coloniality proposed by Mignolo (2007). This allows
\end{abstract}


Rocío QuisPe-AgnOLI

me to read Guamán Poma's chronicle as an example of delinking from the rhetoric of modernity that dominates historiography about Indigenous Americas.

Keywords: Supay, fox, devil, sorcerer, silence, resemantization.

Recibido: 2/11/14 Aceptado: 28/11/14 Publicado on line: 10/1/15

En el año 1615, Felipe Guamán Poma de Ayala, un indio nativo de Huamanga en los Andes sur centrales del Perú, terminó de escribir su voluminosa historia de los Andes. Si bien el autor andino no logró la publicación a la que aspiraba en el siglo XVII, casi 400 años después, en 2007, la Nueva corónica y buen gobierno fue añadida al registro "Memoria del Mundo" de la UNESCO que la reconoció como uno de los documentos con significación mundial. La crónica de Guamán Poma de Ayala ha sido estudiada como ejemplo de apropiación, resistencia y negociación indígena con el poder colonial europeo. Ha sido también analizada como una respuesta alternativa a las historias del hombre andino que los autores europeos escribieron a partir del siglo XVI. ${ }^{1}$ Una función de esta respuesta alternativa se encuentra en la reflexión que ve esta obra como un ejemplo de desprendimiento de la retórica de la modernidad y de la lógica de la colonialidad (Mignolo 2007, 2011). En este ensayo abordo un ejemplo de la retórica escrita e icónico-visual guamanpumiana que llama la atención por los posibles efectos de su ambivalencia discursiva. Me refiero al tratamiento de la otredad maligna en el mundo andino y los silencios del cronista andino al respecto.

Un ejemplo de estos silencios se encuentra en el capítulo acerca de las supersticiones y deidades veneradas por los Incas que el autor incluyó en Nueva corónica: "Capítulo de los idolos, Huaca Billca Incap [divinidades del Inca]" (1987: 262-288). ${ }^{2}$ En la página 279, el autor indígena representó actos de hechicería prehispánica. En esta imagen se observa a los hechizeros que invocaban a los demonios para hablar con ellos. Lo que me llama la atención aquí es el silencio de Guamán Poma ante la palabra supay que, a diferencia de su registro en diccionarios y gramáticas del quechua pastoral del siglo XVI, no aparece escrita ni en el texto que describe este ritual ni en su dibujo. Cuando se refiere a los hechiceros, Guamán Poma utiliza más bien la palabra castellana pontífice que establece una asociación con el clero de la Iglesia católica: "Los pontífices [obispos, papas] hichezeros laycaconas, umoconas, uizaconas, camascaconas que tenía el Inga tenía, lo adoraban y respetaban" (279). Estos hechiceros

1 Los estudios de la Nueva corónica y buen gobierno que se han hecho con estas aproximaciones son muchos y no puedo citarlos todos aquí. Como muestra menciono, en orden alfabético, trabajos que cito para otros puntos en este ensayo como los de Rolena Adorno (1986-2012), Brokaw (2002), Frame (2007), López-Baralt (1989), Pratt (1991) y Quispe-Agnoli (2005, 2006).

2 Para las citas del texto, uso la edición de Adorno, Murra y Urioste (1987). 
invocaban y conversaban con demonios que se dibujaban con los atributos del diablo del medioevo cristiano. Sin embargo, páginas más adelante leemos acerca de un hechicero principal Inca, rodeado por animales que se asociaban con supersticiones y encantamientos. Entre dicho animales, el zorro aparece con un animal pequeño en el hocico mientras el autor escribe en quechua "Atoc zupayta ayzan camaquita ayzan." ["el zorro arrastra al demonio, arrastra a su creador"] (283). ${ }^{3}$ Aparte de esta ocurrencia en el capítulo de las supersticiones Incas, Guamán Poma no utiliza supay ${ }^{4}$ con frecuencia y mantiene un silencio enigmático acerca de este término de manera semejante a su silencio o mínima expresión de otros vocablos quechuas y aymaras. En este trabajo comento el contexto discursivo de estos silencios a partir del tratamiento guamanpumiano de supay y en comparación con otras fuentes andinas coloniales, tanto españolas como indígenas. Mi objetivo es sentar las bases para una posible explicación del silencio de autores nativos de los Andes cuando eligen suprimir o mantener la ambivalencia de referentes o significados de ciertos términos Quechua.

En la multiplicidad de temas que la obra de Guamán Poma de Ayala ofrece para los estudios del Perú colonial y la subjetividad andina, uno de los más reveladores de su lugar de enunciación es el silencio. El silencio puede entenderse como un tema en sí mismo así como una estrategia retórica que se utiliza para negociar de la mejor manera posible el lugar del texto, su producción y difusión, en la "zona de contacto" que inauguraron los decires coloniales. ${ }^{5}$ Es necesario distinguir entre un silencio voluntario que el autor expresa claramente en su escritura como sucede con las frases "escribirlo en nunca acabar" o "no lo escribo por evitar prolixidad" (Quispe-Agnoli 2006). En este caso, el silencio guamanpumiano parece una elección del autor por razones u objetivos retóricos: es tanto lo que se puede escribir, que no es posible escribirlo porque no alcanza el papel o porque el escritor no quiere cansar a su lector con excesivas repeticiones. Este parece ser también el caso de las

3 Reproduzco esta cita tal como aparece en la edición de 1987. La frase en quechua aparece en cursiva y su traducción al español immediatamente entre corchetes. El énfasis en negrita en ésta y las citas siguientes es mío.

4 Supay se escribe de diferentes maneras (Zupay, Çupay, Supai, Hupai, Hupee). En este trabajo mantengo las escrituras de supay ofrecidas por cada autor cuando comento sus textos. En mis comentarios propios, uso supay ya que es la forma castellanizada más ampliamante usada en los diccionarios contemporáneos del Quechua.

5 En su ensayo "Art of the Contact Zone," Mary Louise Pratt propuso "contact zone" para definir aquellos espacios de negociación cultural y lingüística entre sujetos de diferentes horizontes culturales que están forzados a coexistir por circunstancias históricas (1991: 34-35). Sin embargo, años antes, el término fue propuesto en castellano como "zona de contacto" por Rolena Adorno en su introducción a la obra de Guamán Poma de Ayala en su edición de 1987 (xvii-xviii). Adorno aclara esta información en su ensayo reciente sobre el autor andino y su negociación con las leyes españolas (2012: 80, nota 1). 
omisiones de sus fuentes historiográficas españolas, un tema que ha tratado en detalle Rolena Adorno en su libro de 1986 y en un artículo reciente (2012). Hay además que considerar los silencios del autor cuando se trata de conceptos o términos quechua que no se traducen al castellano y/o no se explican en detalle, lo que ofrece una diferencia con el uso de la glosa que el Inca Garcilaso de la Vega ofrece en sus Comentarios reales. Este es el caso de muchos vocablos andinos cuya traducción (o ausencia de traducción) ha sido estudiada por Jorge Urioste en la edición de 1987 que citamos aquí. Otro ejemplo del silencio guamanpumiano se encuentra en Qellqay (quilca), uno de los conceptos claves para entender cómo Guamán Poma asumió el concepto de escritura alfabética en oposición o en combinación con sistemas andinos de comunicación. En mi estudio sobre este término, observé que el cronista andino lo nombra pocas veces, sin explicarlo ni aclararlo (Quispe-Agnoli 2005). Algo semejante parece ocurrir con los diseños de tocapu por medio de signos numéricos en las túnicas de los Incas nobles, cuya evidencia icónico-visual no se explica en el texto escrito (Brokaw 2002, Frame 2007, Urton 1997). La propuesta recurrente en estos estudios es el reconocimiento de la carga significativa del silencio, voluntario o inconsciente, que se aplica al uso, traducción o explicación de términos quechuas o de sistemas semióticos andinos, y la función que dicho silencio cumple en la la retórica del texto guamanpumiano.

Una forma de buscar la voz indígena en las entrelíneas de textos europeos, se encuentra en el estudio de Margarita Zamora sobre las voces taínas en el discurso del descubrimiento de Cristóbal Colón (1999: 191-205). En este ensayo Zamora propone leer los textos colombinos a partir de un lugar de enunciación que revele los actos taínos de habla y su consecuente agencia. En trabajos recientes, Walter Mignolo ha reiterado su aproximación a la obra de Guamán Poma como un ejemplo de desprendimiento de las formas europeas de mirar a los indios (2011). Mignolo analiza el aparente silencio de los indios en los grabados de Theodor de Bry y el contraste de este silencio con la elocuencia retórica del sujeto andino en la crónica. En este contexto de reflexión acerca de los silencios, omisiones y lecturas incompletas que se han hecho de la obra del indio ladino, propongo examinar supay como término y concepto asociado con entidades sobrenaturales que los autores españoles redujeron a sinónimos de otredad maligna en los Andes sin prestar atención a su compleja red semántica.

Varios estudios han analizado el proceso cognoscitivo de Europa en el siglo XVI (O'Gorman 1958; Pastor 1983; Jara y Spadaccini 1989; Mignolo 2005). En el marco de la mentalidad medieval cristiana y sus creencias apocalípticas acerca del mundo, las fuerzas del bien y el mal se enfrentaron en batallas por la posesión (caída o salvación) de las almas de los hombres y sus identidades ideales (Duviols 1972; Gruzinski 2001; MacCormack 1991; Mills 1997; Borja 
1998). El examen cuidadoso que Serge Gruzinski ha hecho acerca de la imaginería visual europea y los atributos de funciones sobrenaturales a objetos sagrados como los cemíes en las islas del Caribe explica el proceso cognoscitivo europeo ante artefactos taínos que se convirtieron en portadores de figuras fantasmales, espectros y, eventualmente, demonios (2001: 18). El estudio de Gruzinski me sirve como punto de partida para examinar la idea europea de identidades ideales en los siglos XVI y XVII, desde la cual se estableció una relación de contiguiidad entre lo sagrado indígena y la otredad maligna.

La otredad maligna constituye la posición más extrema de rechazo social en la que los discursos religiosos de una sociedad colocan a un sujeto. El sistema ideológico de valores del bien y el mal, Dios y el diablo, cielo e infierno, ha desempeñado una influencia decisiva sobre la interacción entre indios y europeos desde el siglo XV. Los viajes de Colón abrieron el Nuevo Mundo a la conversión cristiana y, con ello, al reconocimiento de la otredad maligna en sus habitantes. Exploradores y frailes buscaron en las lenguas indígenas las palabras que podían designar las ideas europeas del bien y el mal, Dios y su creación, el alma y el pecado, los ángeles y los demonios.

En los siglos que siguieron a los viajes de Colón, la episteme europea operó una nueva referencialidad de los objetos de culto sagrado indígena y los resemantizó como espacios de la otredad maligna. En el caso de los Andes, ejemplos significativos de esta resemantización se encuentran en términos del Quechua que originalmente designaban identidades de lo sagrado como camac, huaca, samay, and supay. Estos términos fueron también colonizados por los discursos eclesiásticos del cristianismo y convertidos en manifestaciones del demonio. Entre ellos, supay se usaba como una forma de referencia al (o a los) espíritu(s) del mundo subterráneo andino, pero fue descrito como una entidad fantasmal. Una revisión de los posibles significados prehispánicos de supay puede ayudarnos a entender su distorsión en la colonia.

En su Lexicon o Vocabulario de la lengua general del Perú (1560), Domingo de Santo Tomás definió supay como una palabra para designar espíritus en un sentido similar a la idea de fantasma o espectro que Pedro Mártir de Anglería propuso para los cemíes en el Caribe. Entre la fecha de publicación del Lexicón de Santo Tomás y 1584, año en que empezaron a publicarse otros diccionarios y crónicas de Indias, ocurrió un cambio en el registro y/o traducción de esta palabra. Los autores españoles de Gramáticas, Vocabularios y obras semejantes empezaron a identificar formaciones rocosas o cerros como portadores de espectros y se describieron como lugares del mal. En su artículo "Supay" de 1980, Gerald Taylor exploró la historia linguiística del término y sus posibles significados prehispánicos más allá de las traducciones españolas aprobadas por el Tercer Concilio Limense (1583-1584) para el quechua pastoral. Taylor 
partió del estudio que Pierre Duviols hizo de esta palabra en su libro sobre las extirpaciones de idolatría en los Andes (1972). Duviols citó entonces a tres cronistas de indias -Pedro Cieza de León, Crónica del Perú (1553) Fray Juan de San Pedro, Crónica Agustina de Huamachuco (1560) y el Inca Garcilaso de la Vega, Comentarios reales de los Incas (1609)- que escribieron supay como sinónimo del diablo. Cieza de León, por ejemplo, refirió que el demonio, a quien los indios llamaban supay, se aparecía en formas distintas y les hablaba acerca de la vida placentera más allá de la muerte (1553: 186-187). Cieza caracterizó a supay como un espíritu tramposo que intentaba engañar a los indios para que éstos continuaran con sus prácticas idolátricas. Esta forma de comprender supay será recurrente en las traducciones al castellano como duende, un espíritu travieso que persuadía con su carisma. Por su parte, la crónica de San Pedro describió a supay con los atributos tradicionales del diablo en el cristianismo, una entidad maligna que atraía y aterrorizaba a los indios: "El gran temor que tiene al demonio que ellos llaman çupay y a las guacas e ydolos" (169). A diferencia de Guamán Poma, San Pedro utilizó la palabra supay de manera frecuente en el capítulo dedicado a los hechiceros andinos y sus rituales en los que peleaban por el alma de un hombre en nombre de su amo, el demonio (166-172). El tercer documento que Duviols citó fue Comentarios reales en el cual el Inca Garcilaso escribió que supay era el nombre del diablo en Quechua. Taylor observa aquí que el Inca Garcilaso estaba tratando de corregir el error de los autores españoles quienes habían traducido Pachacamac, la divinidad andina que animaba (camac) el mundo (Pacha), con el diablo. En su defensa, el Inca Garcilaso aclaró que los indios no adoraban a Pachacamac como una divinidad opuesta o diferente a Dios. A diferencia de Pachacamac, el Inca Garcilaso llamó "Zupay" al diablo el cual no era adorado por los indios sino más bien temido y despreciado (1985: I, 63). A partir de las tres crónicas citadas por Duviols, Taylor anotó cuán eficiente había sido la intervención de la Iglesia Católica al traducir huacas y supay como demonios (1980: 48). El impacto del discurso de conversión cristiana se aprecia en los esfuerzos del Inca Garcilaso para remover cualquier identificación de Pachacamac con supay, así como en el silencio o parquedad de Guaman Poma al respecto.

Como he mencionado en páginas anteriores, representaciones del diablo aparecen asociadas con varios rituales Incas en la obra de Guamán Poma de Ayala. Pero no es éste el caso de supay ante el cual el autor se mantiene silencioso. El dibujo que inicia la sección sobre hechiceros (1987: 276-282) del "Capítulo de los idolos," presenta a estos personajes invocando a los demonios para hablar con ellos, pero la palabra supay no aparece ni en el dibujo ni en el texto escrito (279). Sin embargo, en la sección sobre supersticiones y aguieros (283-285), el autor describe a un hechicero Inca rodeado de varios 
animales entre los cuales aparece un zorro en primer plano. En relación al zorro, Guaman Poma escribe: "Atoc zupayta ayzan camaquita ayzan [el zorro arrastra al demonio, arrastra a su creador]" (283). En este dibujo, el zorro arrastra (ayzan o ayçani) en su hocico lo que parece ser un pequeño reptil o un insecto grande. Este acto alude a una superstición de la época, una abución o agüero que era, a su vez, interpretado por el hechicero Inca. Supay aparece aquí con su significado de visión sobrenatural, un fantasma o sombra del mundo subterráneo que anunciaba la muerte. En este punto es necesario revisar las asociaciones prehispánicas entre supay, muerte y ritos funerarios que Taylor distinguió en su estudio de 1980.

El examen de supay en la literatura religiosa de los siglos XVI y XVII dio como resultado su traducción usual como "diablo o demonio" (Santo Tomás 1560, González Holguín 1608, Tercer Concilio 1584). Sin embargo, esta palabra se registra en diccionarios contemporáneos de quechua con el significado de "sombra." Esta traducción revela su relación con otras palabras quechua cuyos posibles significados confirmaban su asociación con la muerte. Es el caso del quechua hupani (sombra de una persona o animal al atardecer), hupay (alma, espíritu), y hupee (espíritu, alma y fantasma) (Taylor 1980: 49). En opinión de Taylor, he aquí la asociación semántica entre supay y muerte: perder la vida era equivalente a morir y convertirse en una sombra o fantasma (50). Más aún, el linguiista explicó que los ritos funerarios y la preparación del occiso para su viaje más allá de la muerte expresaban la necesidad de evitar que se convirtiera en un espíritu maligno. Si esta preparación no se llevaba a cabo correctamente, el difunto andino podría convertirse en un condenado, una entidad maligna traída por los europeos que aludía a aquéllos que habían fallecido sin arrepentimiento o habían hecho un pacto con el diablo (50).

El aguiero del zorro que lleva un insecto o reptil en su hocico, al que Guamán Poma llama supay, es una de las pocas ocurrencias de esta palabra quechua en la Nueva corónica y buen gobierno. Pero el cronista no lo traduce al castellano. En la página que hace referencia a este dibujo, Guamán Poma reitera la asociación entre este agüero y la muerte en quechua:

Quando le paresen o se les entran en sus casas las culebras y cantar de lechuzas y muchuelos, morciégalos que los llaman tuco, chucic, pacpac, pecpe, chicollom, cayaycuuan. Taparanco yaycuuan. Uro nina, ayacta ayzaycuuan. Ychapas maycan uanoson. Atocmi zupayta ayzan uarmitam ychapas carita. [El buho, la lechuza, el paq paq, p'iqpi, chiqallu (especies de buhos) me han llamado. Una mariposa nocturna ha entrado dentro de mí. Los fuegos fatuos me han arrastrado el cadáver. ¿Quizá cuándo vamos a morir? Por cierto, el zorro ha arrastrado al demonio, a una mujer o quizás a un hombre]" (1987: 284, énfasis mío). 
Enseguida, el cronista menciona "oyendo bramar de las sorras o algún animal" como ejemplo de un anuncio de muerte (285). J. van Kessel ha analizado 17 leyendas andinas que incluyen al zorro asociado con daños y percances y mantiene una relación de eterna enemistad con el hombre (1994: 233). En la literatura oral que examina van Kessel, el zorro se agrupa con animales silvestres (puma, armadillo, guanaco, el ave suri) que forman parte de los "animales del diablo" en oposición a los "animales de Dios" que han sido domesticados (llama, alpaca). Sin embargo, el zorro es un símbolo ambivalente. En el Manuscrito de Huarochirí, por ejemplo, este animal conoce los secretos del héroe Tamtañamca pero se rehúsa a ayudar a la huaca Cuniraya Huiracocha por lo cual es objeto de la maldición que lo indispone con los hombres (1987: 85-119). Por otro lado, apunta van Kessel, el zorro es el "perro del Mallku" (espíritu de la montaña que protege a la comunidad) y/o el "perro de los gentiles" que protege las casas de los antepasados difuntos y las chullpas en los que se encuentran enterrados (1994: 233).

La palabra supay aparece por segunda vez en el capítulo de los ídolos como elemento principal de una maldición entre hechiceros:

Maldeciones que echauan entre ellos: Lo primero dizen: "Zupay apasunqui, maypi ysmoc tantay uarina puric, mana pacuspa causac ayamanpas chunca mita cutic runa, camacniquip micuscan, yntip llacsascan, pachap millpuscan. [Que el diablo te lleve, donde se pudre mi pan, a vagar, como una warina, a vivir sin cesar como un hombre que se convierte en cadáver por diez veces, devorado por tu criador, derretido por el sol, tragado por la tierra.]" (1987: 285, énfasis mío).

A partir de la traducción del Quechua que hace Urioste aquí, observemos la contiguiidad semántica entre la idea del zorro que arrastra a supay en el hocico y supay como el demonio mismo que arrastra el alma de los hombres a una muerte más allá de la muerte. En la sección siguiente del mismo capítulo sobre los ídolos, dedicada a las procesiones, ayunos y penitencias (286-288), Guamán Poma menciona al demonio en castellano sin hacer alusión a supay. En este caso, el cronista andino relaciona el demonio con las huacas cuyo culto fue impuesto por los Incas. Impulsados por el miedo, escribe Guamán Poma, los andinos fabricaron ídolos de piedra, madera o barro, que nombraron y veneraron como huacas, propiciando de esta manera la incursión de la otredad maligna que el cristianismo condenaba: "Y ancí entraua los demonios en ellos con las serimonias que mandó el Ynga en este rreyno" (288).

En contraste con estos ejemplos, varias secciones del capítulo de los ídolos y de otros capítulos que tratan de rituales incluyen dibujos y descripciones de diablos y demonios pero Guamán Poma no menciona supay. Estos diablos se representan en la Coronica siguiendo la iconografía europea medieval en episodios que se ocupan de los conjuros de hechiceros y la ebriedad ritual. 
En el caso de los conjuros, las secciones "Pontifises" (279-280) y "Hichizeros de zueños" (281-282) muestran a estos mediadores entre el mundo natural y sobrenatural interactuando con demonios con cuernos, colas, orejas y narices puntiagudas y alas de murciélago. La palabra pontifice designa a hechiceros principales incas que se distinguen por su camisas con tocapus y adornos de la cabeza. La escena que se representa en el dibujo de la página 279 , se explica de la siguiente manera:

A dichos hichezeros dizen los quales tomauan una olla nueua que llaman ari manca, que lo cuecen cin cosa nenguna y toma sebo de personas y mays y zanco y plumas y coca y plata, oro y todas las comidas. Dizen que los echan dentro de la olla y los quema muy mucho y con ello habla el hechizero, que de dentro de la ola hablan los demonios. (280)

El demonio que aparece sentado en la olla no se describe en el texto escrito. Aún así es fácil reconocer el modelo utilizado por Guamán Poma que responde a la iconografía cristiana del ángel caído en la tradición europea. En su estudio sobre la figura de Lucifer en la edad media, Jeffrey Russell ha analizado este modelo en la ilustración que representa al "diablo ante el Papa Silvestre II" en el siglo XV (1984). Russell describe esta imagen con gran detalle visual:

Often the Devil appears as monstrous and deformed, his outward shape betraying his inner defect. He is lame because of his fall from heaven; his knees are backward; he has an extra face on belly, knees, or buttocks; he is blind; he has horns and a tail; he has no nostrils or only one; he has no eyebrows; his eyes are saucer like and glow or shoot fire; he has cloven hooves; he emits a sulphurous odor, and when he departs he does so with stench, noise and smoke; he is covered with coarse, black hair; he has misshapen, bat like wings. Iconographically he becomes much like Pan, horned, hooved, covered with goat hair, with a large phallus and a large nose, and with Saturnine features. (68)

Hacia el final del texto acerca de los hechiceros incas, Guamán Poma escribe otras palabras castellanas (duende, espíritu, fantasma) con las que se había traducido supay en los diccionarios coloniales del siglo XVI: "En tienpo de los Yngas andauan duendes y malos espíritus entre los yndios y ancí abía fantasma de los Chinchay Suyos, Ande Suyos en Anliay Pampa y de los Colla Suyos, Conde Suyos en Caray Cinga y en los Puquinas. Porque dezían que allí andaua todas las ánimas de los muertos, padeciendo hambre y sed y calor y frío y fuego" (280, énfasis mío). Observemos en esta cita que Guamán Poma no menciona la palabra supay aunque sí alude a sus traducciones castellanas que no solo incluyen formas de otredad maligna desde el punto de vista cristiano de dichos diccionarios sino también la idea de las almas de aquéllos que andan perdidos en el mundo o los condenados que mencionó Taylor (1980:50). En la sección sobre los hechiceros de sueños, el autor andino representa a los 
hechiceros comunes que no pertenecían a altos rangos Incas pero invocaban y hablaban con demonios (281). En este segmento el autor andino distingue tres tipos de hechiceros: de sueño, los que chupan enfermedades y los de fuego. El acusa a todos de falsos: llulla laica umu o "brujos mentirosos." Más aún, Guamán Poma declara que estos hechiceros engañaban a hombres, mujeres y al mismo demonio, ${ }^{6}$ y que habían aprendido sus artes del Inca (282). A continuación, el cronista establece una correspondencia ambigua entre los hechiceros principales Incas -a los que llama pontífices- y los oficiales de la Iglesia Católica. Es difícil dilucidar si el cronista está cometiendo un error de interpretación, si está evitando la censura a las prácticas rituales andinas a pesar de invocar demonios en el sentido cristiano, o si está haciendo una crítica de obispos, clérigos y sacerdotes cristianos:

Los pontífises como ca[r]denales y obispos puesto de los Yngas en los más prencipales uacas, fuera de la uaca ýdolo del Ynga, como dicho es (...) Los hichezeros que fueron como canónigos en las uacas mayores (...), seruían asalariados y pagados estos hichezeros de los Yngas. Los hichezeros como sazerdotes que seruían en los guamanies [provincia] y por los apachitas [adoratorio] y común uacas ýdolos, dioses, que abía muchas en el rreyno. Serbían estos saserdotes confesores; éstos engañauan a los hombres, deziendo que come y ueue y habla las uacas, no lo haziendo. (282)

Otra instancia que vale la pena examinar aquí es el capítulo dedicado a los capitanes y señoras Incas (1987: 145-183). Aquí encontramos una representación del Tercer Capitán del ejército inca, Cusi Huanchire cuyo alto rango militar se expresaba por medio de los tocapus en su túnica, el penacho sobre su cabeza y otros accesorios como las orejeras y sus armas (149). Este capitán está de pie mientras sostiene en la mano derecha un vaso ceremonial o kero que contiene chicha que bebe mientras, en la otra mano, sostiene una ofrenda al dios sol ubicado en la esquina superior derecha del dibujo. El texto que explica este dibujo dice que el capitán bebía con el dios sol, antes de ir a una batalla. La ausencia de una figura demoniaca en esta escena de un ritual prehispánico es significativa para el lector europeo. En este dibujo, Guamán Poma nos recuerda la bebida ritual como un evento controlado y beneficioso en el cual el guerrero inca honraba al dios sol para que lo defendiera en sus batallas.

Otro dibujo, sin embargo, ofrece un contraste significativo a la imagen anterior (100). Se muestra aquí al quinto Inca, Capac Yupanqui, en un ritual en el cual bebe con el dios sol, pero hay una figura adicional. Se trata de un demonio

6 Esta alusión de engañar al mismo demonio puede ser un error de escritura del mismo autor. La cita permanece ambivalente: "Estos dichos son falsos hichezeros; engaña a los yndios y al demonio sólo a fin de engañalle su hazienda y enseñalle a los yndios ydúlatras" (282). 
volador en la esquina superior derecha que, en la distribución espacial andina, se solía reservar para la divinidad. Extraído de la literatura y arte cristianos de su época, esta imagen del diablo se inserta en el dibujo de Guamán Poma como un mediador entre el rey Inca, el dios sol y el acto de la bebida ritual que eventualmente se convierte en el vicio de la borrachera. Según la descripción que se ofrece en la página siguiente, el Inca Capac Yupanqui solía beber con su padre, el dios sol, y alimentaba las huacas e ídolos. Más aún, declara el autor, el descubrimiento de minas de oro y plata, uno de los pilares fundacionales del imperio Inca, fue posible gracias a demonios como éste que guiaron al Inca para encontrar dichos repositorios. De esta manera, el autor usó la figura medieval del diablo para censurar la bebida ritual como una ceremonia demónica. Con el fin de apoyar esta idea, Guamán Poma ofrece dos razones: en primer lugar, esta ceremonia no servía a una causa noble como era el caso del Tercer Capitán mencionado antes. Desde un punto de vista cristiano, la ceremonia en la que el Inca Capac Yupanqui bebe con el dios sol es un ejemplo de su avaricia. En segundo lugar, Guamán Poma rechaza a los Incas como el grupo étnico dominante en los Andes del siglo XV. La rivalidad entre Incas y miembros de las noblezas locales subyugadas por éstos, entre las cuales se pudo incluir la del mismo autor, lo llevó a declarar que la conquista de los Andes fue un castigo a la idolatría de los Incas. Más aún, en la sección que inaugura el capítulo de las biografías de los reyes incas, la madre de Manco Cápac, fundadora de la dinastía, es descrita como una mujer idólatra y hechicera que hablaba con los demonios (1987: 81).

El siguiente dibujo que incluye la figura del diablo aparece en el capítulo de los meses del año (237-262) y nos ofrece una narrativa visual con tres actos que empiezan en la esquina inferior derecha. (248). Una mujer arrodillada sirve chicha de una vasija ceremonial (aríbalo) en un kero que coloca a los pies del Inca. Enseguida, el Inca bebe del vaso mientras mira al dios sol. Finalmente un demonio que vuela en dirección al sol, lleva el vaso de chicha y se lo ofrece. El texto verbal en el dibujo explica la secuencia: "Junio. Hauca Cusqui [descanso de la cosecha]. Bebe con la fiesta del sol" (248) Según el Vocabulario de Gonzalez Holguín, haucaicusqui significaba haucai- "tomar un descanso, ocioso, sin trabajos ni ocupación" mientras que cusqui-y significaba "encontrar algo sin mucho esfuerzo" (1989: 72). Por lo tanto "Haucaicusqui" parece referir al mes de junio en que se celebraba la fiesta del sol o Inti Raymi. Esta fecha también indicaba el inicio de la recolección de datos, cuentas y recursos del imperio. Hasta aquí, la presencia de la figura del diablo en los dos últimos dibujos indica la naturaleza idolátrica de los rituales Incas según la opinión cristiana. La asociación entre el diablo y la borrachera ritual se expande en la figura que aparece en la página 876 de Buen gobierno. El título del dibujo dice: "Indios. 
La Borrachera. Maschasqa [emborrachado]." Una mujer india toca un tambor mientras un hombre indio vomita frente a ella. Sobre los hombros de este sujeto, hay un demonio de tamaño humano que empuja su cabeza hacia abajo. En contraste con las figuras de demonios en los dibujos anteriores, éste es mucho más grande y su apariencia deforme es más detallada. Además, este demonio parece tener la apariencia de una mujer anciana con pechos colgantes y una cola larga que se enrosca en el cuello del indio borracho. El demonio lo controla y, al mismo tiempo, anima la música que toca la mujer. La apariencia de este demonio recuerda a hapuñuñu, un fantasma o duende cuyo nombre se registra en el Vocabulario de González Holguín como fantasma o duende con pechos grandes y feos (Taylor 1980: 54). Este supay femenino solía tomar la forma de una mujer seductora que trataba de distraer al héroe de las historias y no se le entendía como demonio sino como duende. El dibujo de Guamán Poma presenta a un diablo femenino responsable por el vicio del indio y la idolatría de la india. El diablo de este dibujo tiene características de hapuñuñu y, sin embargo, Guamán Poma opta por guardar silencio. El cronista no escribe ni hapuñuñu ni supay y deja que el lector español lo interprete como el diablo de la iconografía cristiana que es el responsable por la destrucción de los indios.

El estudio de Mercedes Lopez-Baralt (1988) sobre la iconografía de vicios y virtudes en la obra de Guamán Poma, ha determinado que los únicos vicios asociados a los indios de la colonia por el autor fueron la ociosidad y la ebriedad. Ambos constituían razón suficiente para colocar al indio en las fauces del infierno al lado de españoles pecadores (López Baralt 305, Guaman Poma 1987: 950, 955) porque el indio borracho, aun cristiano, hablaba con los demonios y rendía culto a las huacas (1987: 877). Esta idea ofrece un contraste agudo con la bebida ritual prehispánica: "Que en tiempo de los Yngas, y ací no avía borrachería, aunque vevían y hacían fiestas y más estaba vedado de que las mugeres no se emborrachase, grandes castigos en ellas" (877). Guamán Poma distinguió entre la forma respetable andina e Inca de la bebida ritual en una ceremonia y la borrachera como el consumo abusivo de alcohol que favorecía la interacción con el diablo. En su excelente artículo sobre la imaginería de la ebriedad, Mónica Morales explicó la distinción que hace Guamán Poma entre moderación y exceso. La primera mantiene el control sobre las pasiones, mientras que la segunda se convierte en un elemento social conflictivo equivalente al desorden moral y político (2009: 449).

Un examen de las Ordenanzas (1569-1582) del virrey Francisco de Toledo revela además que la intención oficial era regular las prácticas y estilos de vida indígenas bajo el poder colonial. Sin embargo, como Morales demuestra, las medidas de Toledo funcionaron más bien como una red de iniciativas destinada a desacreditar a los Incas como tiranos. La ebriedad, añade Morales, sirvió como 
una plataforma en la que se justificaba la imposición de las leyes españolas sobre los indios que eran incapaces de gobernarse a sí mismos (455). En este contexto, Toledo trató de demostrar que los indios eran débiles, sensuales, presa fácil de los vicios, siendo el alcohol uno de los peores porque les facilitaba continuar con sus prácticas idolátricas. Guamán Poma conoció las Ordenanzas de Toledo y su repercusión sobre el hombre andino. La figura del diablo europeo en sus dibujos no aparece cuando habla de los vicios de los españoles y sus abusos de los indios. Pero sí hay otras imágenes de la iconografía medieval de bestias que atormentaban al buen cristiano y a los pobres indios. La cárcel prehispánica, que se describe en el capítulo sobre la justicia Inca, representa a un indio que es castigado por sus crímenes y encerrado en una cueva con animales salvajes (304) Este indio de la Nueva corónica lamenta su destino y llora. En el Buen gobierno, una imaginería similar representa al pobre indio que sufre los abusos de españoles diabólicos (708). En este dibujo, el indio desempeña el rol del mártir cristiano rodeado de animales que están a punto de devorarlo. Dichos animales son alegorías de las autoridades coloniales. Estamos ante una manifestación icónico-visual del tema del mundo al revés que el cronista usó para expresar cómo el bien y el mal habían cambiado posiciones en los Andes coloniales. En lugar de un hombre deformado por cuernos, colas, pezuñas y alas de murciélago, los oficiales españoles son "animales del diablo" que han tomado el lugar de pumas, armadillos y zorros.

Para concluir, el silencio de Guaman Poma de Ayala ante supay, y sus traducciones flexibles, se compensa con la inclusión del diablo de la iconografía medieval cristiana que invade el espacio ritual andino. En su visión del mundo andino, el diablo no se manifestó hasta la imposición idolátrica de los Incas movidos por la avaricia, y la llegada de los españoles que lo trajeron consigo. La reducción de supay en el diablo y sus ídolos buscó eliminar cualquier significado de lo sagrado andino, lo que constituye para nosotros un elemento clave para entender la subjetividad indígena. En la respuesta andina a estos cambios de sentido, los hechiceros se convirtieron en pontífices buenos o malos; las ceremonias que incorporaban bebidas rituales se tornaron en borracheras viciosas de los indios cristianos porque éstos habían abandonado su identidad original y se parecían cada vez más a los conquistadores; el diablo de la imaginación medieval europea irrumpió en los Andes para quedarse mientras que supay (duende, espíritu, fantasma, sombra y alma) se mantuvo en silencio.

\section{Referencias bibliográficas}

ADORNO, Rolena. (1986) Guáman Poma: Writing and Resistance in Colonial Peru. Austin: University of Texas Press.

LETRAS 85 (121), 2014 
Rocío QuisPe-AGNOLI

ADORNO, Rolena. (1987) “Waman Puma: el autor y su obra.” En: Felipe Guamán Poma de Ayala, Nueva corónica y buen gobierno [1615]. Rolena Adorno, John Murra y Jorge Urioste (eds.) Madrid: Historia 16; vol 1, pp. xviii-lxiii.

ADORNO, Rolena. (1991) "Images of Indios Ladinos in Early Colonial Andes." En: Kenneth J. Andrien \& Rolena Adorno (eds.) Transatlantic Encounters: Europeans and Andeans in the Sixteenth Century, Berkeley: University of California Press; pp. 232270.

ADORNO, Rolena. (2003) “A Witness Unto Itself.” En: Rolena Adorno \& Ivan Bosserup (eds.) New Studies of the Autograph Manuscript of Felipe Guaman Poma de Ayala. Copenhague: Museum Tusculanum Press; pp. 7-106.

ADORNO, Rolena (2012). "Court and Chronicle: A Native Andean Engagement with Spanish Colonial Law.” En: Saliha Belmessous (ed.) Native Claims: Indigenous Law Against Empire, 1500-1920. Oxford: Oxford University Press; pp. 63-84.

AVILA, Francisco de. (1987) [1598-1608] Ritos y Tradiciones de Huarochirí del siglo XVII. Lima: Instituto de Estudios Peruanos.

BORJA GOMEZ, Jaime H. (1998). Rostros y rastros del Demonio en Nueva Granada: Indios, judíos, mujeres y otras huestes de Satanas. Bogotá: Ariel.

BROKAW, Galen. (2002) "Khipu Numeracy and Alphabetic Literacy in the Andes: Felipe Guaman Poma de Ayala's Nueva corónica y buen gobierno” en Colonial Latin American Review. 11.2; pp. 275-303.

CIEZA DE LEON, Pedro. (1962) [1553] La crónica del Perú. Madrid: Biblioteca de autores españoles.

CONCILIO PROVINCIAL DE LIMA. (1584) Doctrina Christiana, y catecismo para la instrucción de los indios. Lima: Antonio Ricardo Impressor.

DUVIOLS, Pierre. (1972) La lutte contre les religions autochtones dans le Pérou colonial. Lima: Instituto Francés de Estudios Andinos.

FRAME, Mary. (2007) "Lo que Guamán Poma nos muestra pero no nos dice acerca de tocapu” en Revista Andina 44; pp. 9-48.

GARCILASO DE LA VEGA, el Inca. (1985) [1609]. Comentarios reales de los Incas. Sucre, Venezuela: Biblioteca Ayacucho. 2 Vols.

GONZALEZ HOLGUIN, Diego. (1989) [1608]Vocabulario de la Lengua General de todo el Peru llamada Lengua Qquichua o del Inca. Lima: Fondo Editorial de la Universidad Nacional Mayor de San Marcos..

GRUZINSKI, Serge. (2001) [1990] The War on Images. Mexico from Columbus to Blade Runner. Durham, NC: Duke University Press.

GUAMAN POMA DE AYALA, Felipe. (1987) [1615]. Nueva corónica y buen gobierno [1615]. Rolena Adorno, John Murra \& George Urioste (eds.). Madrid: Historia 16. 3 Vols.

JARA, René \& Nicolás SPADACCINI (eds.) (1989) 1492-1992: Re/Discovering Colonial Writing. Minneapolis: University of Minnesota Press.

LOPEZ-BARALT, Mercedes. (1988) Icono y conquista. Madrid: Hiperión.

MACCORMACK, Sabine. (1991). Religion in the Andes: Vision and Imagination in Early Colonial Peru. Princeton, NJ: Princeton University Press.

MIGNOLO, Walter. (2005) The Darker Side of the Renaissance. Ann Arbor: University of Michigan Press. 
El silencio de Guamán Poma de Ayala ante Supay: de duende, espíritu y fantasma a diablo

MIGNOLO, Walter. (2007) "Delinking” en Cultural Studies 21.2; pp. 449-514.

MIGNOLO, Walter. (2011) "Crossing Gazes and the Silence of the "Indians": Theodor De Bry and Guaman Poma de Ayala" en Journal of Medieval and Early Modern Studies. 41.1; pp. 173-223.

MILLS, Kenneth. (1997). Idolatry and its Enemies: Colonial Andean religion and Extirpation, 1640-1750 Princeton, NJ: Princeton University Press.

MORALES, Mónica. (2009) "Inebriation Imagery and 'Epistemic Shift:' The Case of Guamán Poma de Ayala” en Revista de Estudios Hispánicos. 43. 3, pp. 449-470.

O'GORMAN, Edmundo. (1976). La invención de América [1958]. México: Fondo de Cultura Económica.

PASTOR, Beatriz. (1983). Discurso narrativo de la conquista de América. La Habana: Ediciones Casa de las Américas.

PRATT, Mary L. (1991) "Art of the Contact Zone" en Profession 91; pp. 33-40.

QUISPE-AGNOLI, Rocío. (2005) "Cuando Occidente y los Andes se encuentran: Qellqay, escritura alfabética y tokhapu en el siglo XVI" en Colonial Latin American Review. 14.2; pp. 263-298.

QUISPE-AGNOLI, Rocío. (2006) La fe andina en la escritura. Lima: Fondo Editorial de la UNMSM.

RUSSELL, Jeffrey B. (1984) Lucifer: the Devil in the Middle Ages. Ithaca: Cornell University Press.

SAN PEDRO, Fray Juan de. (1992). En: Luis Millones et alia (eds.) La persecución del demonio. Crónica de los primeros Agustinos en el norte de Perú [1560]. Málaga: Algazara.

SANTO TOMAS, Domingo de. (1994) [1560] Gramática o arte de la lengua general de los indios de los reynos del Perú. Lexicon o Vocabulario de la lengua general del Perú.. Rodolfo Cerrón Palomino (trasl.). Madrid: Agencia Española de Cooperación Internacional.

TAYLOR, Gerald. (1980) "Supay.” Amerindia. 5; pp. 47-63.

TAYLOR, Gerald. (1980) "La Plática Breve de la Doctrina Christiana” Amerindia 25; pp. 173-187.

URIOSTE, Jorge. (1987). “Los textos quechuas en la obra de Waman Puma.” En: Guamán Poma de Ayala, Felipe, Nueva crónica y buen gobierno. John V. Murra, Rolena Adorno y Jorge L. Urioste (eds.). Madrid: Historia-16; vol. 1, pp. Ixv-lxxvii.

URTON, Gary. (1997) The Social Life of Numbers. A Quechua Onthology of Numbers. Austin: University of Texas Press.

VAN KESSEL, J.J.M.M. (Julio-Diciembre 1994). "El zorro en la cosmovisión andina.” Revista Chungará. 26.2; pp. 233-242.

ZAMORA, Margarita. (1999) “' 'If Cahonaboa Learns to Speak'...”: Amerindian Voice in the Discourse of Discovery. Colonial Latin American Review 8.2; pp. 191-205. 
